\title{
Breastfeeding and cortisol in hair in children
}

\author{
Johnny Ludvigsson ${ }^{1 *} \mathbb{D}$, Åshild Faresjö ${ }^{2}$ and Tomas Faresjö ${ }^{2}$
}

\begin{abstract}
Background: One of the most important protective health factors for children is breast-feeding, but the mechanisms for this effect are not fully elucidated. Our objective was to assess if the duration of breastfeeding influences cortisol in hair, used as a biomarker for stress in children still at school-age.

Methods: ABIS (All Babies in Southeast Sweden) is a prospective population-based child cohort study of 17,055 children born Oct 1st1997- Oct 1st 1999, with the aim to study development of immune-mediated diseases. Questionnaires were answered at birth and then at regular follow-ups, and biological samples were collected. As a biomarker of stress, we measured the child's cortisol in hair collected at 8 years of age, those randomly selected $N=126$ children among those with enough hair samples for analyses of hair at 8 years of age. Duration of breastfeeding had been registered as well as psycho-social factors related to breastfeeding and/or stress.

Results: There was a negative correlation $(r=-0.23, p=0.01)$ between total duration of breastfeeding and hair cortisol levels at 8 years of age. In a multivariate analysis this association persisted $(p=0.01)$ even when adjusted for other potential intervening factors like age of mother at delivery and early psychosocial vulnerability in the family, an index based on 11 factors (Multivariate model: $\mathrm{df}=5$, adj $\mathrm{R}^{2}=0.15, \mathrm{~F}=5.38, p<0.01$ ).

Conclusion: Our results show that longer breastfeeding is associated with lower cortisol levels in the child many years later. These associations should be more elaborated in further studies, and these findings also give some implications for public health. Mothers should be encouraged to breastfeed their children also in the modern society, since breastfeeding promotes health in the child. This information could be given via the obstetric departments and later at the well-baby clinics.
\end{abstract}

Keywords: Stress, Child public health, Cortisol, Hair, Development, Epidemiology

\section{Background}

Stress is part of the homeostasis associated with health [1]. Transient increased stress either caused by trauma, psychosocial factors, infections etc. can usually be managed by the body [2], while repeated serious stress for instance repeated serious life events such as loss of parents (divorce, death), serious disease in the family [3] or

\footnotetext{
* Correspondence: johnny.ludvigsson@liu.se

${ }^{1}$ Crown Princess Victoria Children's Hospital and Division of Pediatrics,

Department of Biomedical and Clinical Sciences, Linköping University, SE-581 85 Linköping, Sweden

Full list of author information is available at the end of the article
}

chronic stress contribute to increased morbidity. There is no simple way to determine stress over longer time but in recent years cortisol in hair, reflecting the cortisol concentrations of the body for some months since hair grows ca $1 \mathrm{~cm} /$ month [4], has been used as biomarker for long-term stress both in animals $[5,6]$ and in humans $[4,7,8]$. Recent years, also clinical applications of cortisol measurements have emerged [9] such as biomarker of children's stress at school and also parityrelated variations in cortisol concentrations in hair during pregnancy $[10,11]$.

A number of factors in early childhood play an important role for health later in life. Early psychosocial

(C) The Author(s). 2021 Open Access This article is licensed under a Creative Commons Attribution 4.0 International License, which permits use, sharing, adaptation, distribution and reproduction in any medium or format, as long as you give appropriate credit to the original author(s) and the source, provide a link to the Creative Commons licence, and indicate if changes were made. The images or other third party material in this article are included in the article's Creative Commons licence, unless indicated otherwise in a credit line to the material. If material is not included in the article's Creative Commons licence and your intended use is not permitted by statutory regulation or exceeds the permitted use, you will need to obtain permission directly from the copyright holder. To view a copy of this licence, visit http://creativecommons.org/licenses/by/4.0/ The Creative Commons Public Domain Dedication waiver (http://creativecommons.org/publicdomain/zero/1.0/) applies to the data made available in this article, unless otherwise stated in a credit line to the data. 
stress may influence health later in adulthood [12, 13]. One of the most important health factors is breastfeeding $[14,15]$. The mechanisms are regarded to be related to prevention of infections known for very long time [16], influence on the gut flora [17]), effects on the immune system related to maturation of the immune system and development of tolerance against antigens [18]. Breastfeeding with its close contact between mother and child has also profound psychological effects on the child [19]. Duration of breastfeeding is related to several factors such as age and social circumstances of the mother, smoking behavior. It is therefore difficult to know what role breastfeeding plays per se. We therefore decided to study whether breast-feeding may influence future cortisol concentration in hair used as a biomarker for stress during childhood, being an important piece of puzzle in our broader studies on the cause of autoimmune diseases, especially Type 1 diabetes, especially as both psychological stress and cortisol causing insulin resistance may play a role for development of Type 1 diabetes [3] .

\section{Methods}

\section{The ABIS-study}

All parents with children born between October 1st in 1997 and October $1^{\text {st }}$ in 1999 in Southeast Sweden $(N=$ 21.700) were asked to participate in the ABIS study (All Babies in Southeast Sweden), a prospective cohort study with the aim to study how genetic and environmental factors contribute to the development of immunemediated diseases, especially Type 1 diabetes [20]. Out of the 21.700 invited families 17.055 (78.6\%) gave their informed consent to participate. Comprehensive questionnaires including up to 1000 questions were answered at birth and then at the age of 1, 3, 5, 8, 12-13 years of age, and biological samples (blood, urine, stool, hair) were collected at the follow-ups. During the first year of life a diary was used for daily registration of certain nutritional data such as time-point for introduction of different food items (among others cow's milk protein, gluten, vegetables), infections, vaccinations, drugs and many more items (Information on questionnaires, in Swedish, can be given on reasonable request). In the questionnaires, parents were asked for duration of breastfeeding. Exclusive breastfeeding means no other food than breast milk and was based on several questions such as: "How long time from birth was the child breastfed and got only breastmilk?" which was validated by other questions about when other food was introduced. Partial breastfeeding is defined as breastfeeding in addition to formula or other food. In this analysis we focus on total breastfeeding, defined as the duration of any breastfeeding (exclusive and partial breastfeeding). The answers by the mothers have been validated by comparison with breastfeeding data registered at the well-baby clinics showing very high agreement.

In earlier follow-up of questionnaire data (from the whole ABIS cohort) one year after birth showed that $78.4 \%$ of infants were exclusively breast-fed at 3 months, $10.1 \%$ at 6 months and $3.9 \%$ up to 9 months. Partially breast-fed children were $68.9 \%$ at 6 months, while $43.6 \%$ were partially breast-fed to at least 9 months of age [21]. The median exclusive breastfeeding duration was four months and the median duration for total breastfeeding eight months. Maternal smoking, high maternal BMI, and being a single mother were associated with shortterm exclusive breastfeeding. Both maternal and paternal age was positively associated with the duration of both exclusive and partial breastfeeding [22] .

In this study we analyzed a subpopulation of ABISchildren and parents since we were interested in studying different psychosocial factors impact on long-term HPA-axis activity i.e. prolonged stress measured by cortisol in hair [8]. This is an important part of the objective of the ABIS study aiming to investigate factors explaining the development of immune-mediated diseases, especially Type 1 diabetes. The 8 years follow-up cohort for ABIS-study consisted of $N=4031$ participants. From these, we randomly selected $n=126$ children that had sufficient hair samples to be analysed and also reliable information about breastfeeding, as well as other relevant data of the child, mother and family. All these children were included, and this number is therefore a randomly selected group from the general population. A power calculation was made estimating that the difference in hair cortisol levels for those with short breastfeeding vs. longer breastfeeding with a desired precision of 0.05 and an estimate of the true proportion of 0.40 and within a confidence interval of 0.95 . This calculation gave an estimated sample of at least 96 participants, so with the selected $n=126$ participants the study power was secured. Duration of breastfeeding was measured through a questionnaire to the mothers one year after the childbirth, when she answered about the duration in months of exclusive and partial breastfeeding. The breastfeeding variable was divided into short until 1 month, 2-6 months (medium), 7 months or longer (longer), but in the regression analyzed as a continues variable. Possible confounding factors include child's gender, child's birth weight (low, normal and high), gestational age (early, normal or over time), type of delivery (vaginal, Cesarean section or other problems), mother parity (first born or earlier parity), age of mother at delivery (range 18-40years), if mother smoked during pregnancy, and a composite index of early psychosocial vulnerability in the family including eleven different indicators: single mothers, unemployment, low family income, housing conditions, low education of father or 
mother (i.e only primary school), parents born abroad (i.e mother or father not born in Sweden), mother experience of serious life events, mother not feeling safe or lack of social support during pregnancy, mother worried that the child could fall ill with serious disease (4).

\section{Measures of cortisol in hair}

Trained staff cut strands of hair from the posterior vertex area of the participants' heads in accordance with guidelines published by the Society of Hair Testing [24]. The hair was then enclosed in sealed plastic tubes marked with identification numbers and stored in room temperature until analysis. All analyses were performed at the laboratory of Clinical Chemistry at the University of Linköping. The first $3 \mathrm{~cm}$ of outgrowth were analyzed for cortisol concentrations using a competitive radioimmunoassay in methanol extract [24]. At least $3 \mathrm{mg}$ of hair was required for reliable measurements. The samples were dissolved in radioimmunoassay buffer and analyzed. Hair samples between 3 and $10 \mathrm{mg}$ were required to maintain a total inter-assay coefficient of variation below $8 \%$ for hair extraction and measurement of cortisol by the radioimmunoassay. The hair samples included in this study were analyzed 4 years after collection. Hair samples and its cortisol content has been found to be very stable over time [23]. The method is fully described elsewhere $[8,24]$.

\section{Statistical analysis}

Statistical analyses was made by using the Statistical Package for the Social Sciences software, version 23 (IBM SPSS Statistics, IBM Corporation). The measured cortisol values were logarithmised before the statistical analysis due to possible skewness in the distribution. In the univariate tests analysis of variance (ANOVA) was used for comparisons of mean. For the association between continued variables, Pearson's correlation coefficient was applied. Variables, statistically significant in the univariate analysis, were included in a multivariate linear regression model. A $p$-value $<0.05$ was considered statistically significant.

\section{Results}

We found an association $(p=0.01 ; \mathrm{r}=-0.23)$ between total length of breastfeeding and hair cortisol levels when the child was 8 year old. The longer the child was breastfed the lower the cortisol in hair, (Fig. 1).

The sociodemographic data and characteristics for study sample $(n=126)$ in relation to the whole cohort at 8 years follow up $(n=3905)$ is shown in Table 1 . The study sample and whole cohort were quite similar in

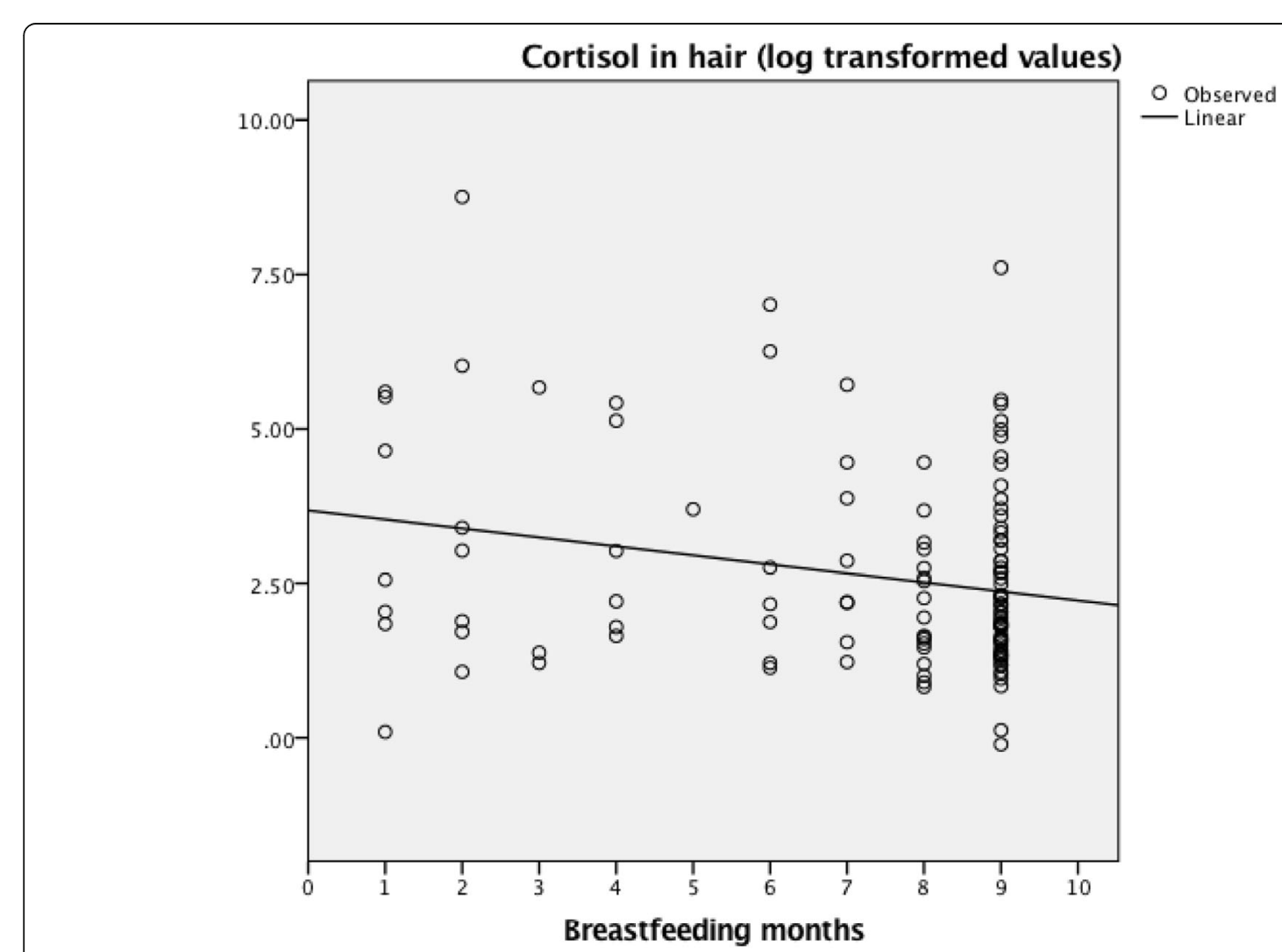

Fig. 1 Duration of breastfeeding (months) and cortisol values (logged) among 8 year old children $(N=126)$ 
Table 1 Sociodemographic data and characteristics for the participants $(n=126)$ in relation to the whole cohort at 8 years follow up $(n=3905)$

\begin{tabular}{|c|c|c|c|c|c|}
\hline \multirow[t]{2}{*}{ Variables } & \multicolumn{2}{|c|}{$\begin{array}{l}\text { Participants } \\
N=126\end{array}$} & \multicolumn{2}{|c|}{$\begin{array}{l}8 \text { years cohort } \\
\mathrm{n}=3905\end{array}$} & \multirow[t]{2}{*}{$\begin{array}{l}\mathrm{p} \text { - } \\
\text { value }\end{array}$} \\
\hline & $\mathbf{n}$ & $\%$ & $\mathbf{n}$ & $\%$ & \\
\hline Gender (children) & & & & & 0.06 \\
\hline Boys & 56 & 44.4 & 2065 & 52.9 & \\
\hline Girls & 70 & 55.6 & 1840 & 47.1 & \\
\hline \multicolumn{6}{|l|}{ Mother education } \\
\hline Low & 34 & 27.0 & 1177 & 30.5 & 0.34 \\
\hline Medium & 44 & 34.9 & 1119 & 29.0 & \\
\hline High & 48 & 38.1 & 1563 & 40.5 & \\
\hline \multicolumn{6}{|l|}{ Father education } \\
\hline Low & 40 & 32.8 & 1222 & 31.9 & 0.43 \\
\hline Medium & 52 & 42.6 & 1469 & 38.3 & \\
\hline High & 30 & 24.6 & 1142 & 28.9 & \\
\hline \multicolumn{6}{|l|}{ Custody at 8 years } \\
\hline Mother and father & 111 & 90.2 & 3443 & 89.9 & 0.90 \\
\hline Single parent & 4 & 3.3 & 107 & 2.8 & \\
\hline Joint custody & 8 & 6.5 & 279 & 7.3 & \\
\hline Mother born abroad & & & & & $<0.01$ \\
\hline yes & 18 & 14.3 & 191 & 4.9 & \\
\hline No & 108 & 85.7 & 3678 & 95.1 & \\
\hline Father born abroad & & & & & 0.14 \\
\hline Yes & 10 & 7.9 & 193 & 5.0 & \\
\hline No & 116 & 92.1 & 3669 & 95.0 & \\
\hline Duration of breastfeeding & & & & & 0.22 \\
\hline Until 1 month & 7 & 5.6 & 102 & 3.3 & \\
\hline $2-6$ months & 22 & 17.7 & 682 & 21.9 & \\
\hline 7 months or more & 95 & 76.6 & 2333 & 74.8 & \\
\hline Birth weight & & & & & 0.92 \\
\hline Low & 12 & 9.5 & 385 & 10.0 & \\
\hline Normal & 100 & 79.4 & 3089 & 80.0 & \\
\hline High & 14 & 11.1 & 387 & 10.0 & \\
\hline \multicolumn{6}{|l|}{ Gestational age } \\
\hline Early & 11 & 8.8 & 310 & 8.1 & 0.97 \\
\hline Normal & 112 & 89.6 & 3435 & 90.2 & \\
\hline Over time & 2 & 1.6 & 63 & 1.7 & \\
\hline Type of delivery & & & & & 0.83 \\
\hline Vaginal & 104 & 83.2 & 3176 & 82.8 & \\
\hline Caesarean section & 13 & 10.4 & 450 & 11.7 & \\
\hline Suction cup & 8 & 6.4 & 209 & 5.4 & \\
\hline Mother parity & & & & & 0.74 \\
\hline Primipara & 53 & 42.4 & 1580 & 40.9 & \\
\hline Multipara & 72 & 57.6 & 2281 & 59.1 & \\
\hline \multicolumn{6}{|l|}{ Age of mother at delivery } \\
\hline $16-20$ years & 2 & 1.6 & 29 & 0.7 & 0.02 \\
\hline
\end{tabular}


Table 1 Sociodemographic data and characteristics for the participants $(n=126)$ in relation to the whole cohort at 8 years follow up $(n=3905)$ (Continued)

\begin{tabular}{|c|c|c|c|c|c|}
\hline \multirow[t]{2}{*}{ Variables } & \multicolumn{2}{|c|}{$\begin{array}{l}\text { Participants } \\
N=126\end{array}$} & \multicolumn{2}{|c|}{$\begin{array}{l}8 \text { years cohort } \\
\mathrm{n}=3905\end{array}$} & \multirow[t]{2}{*}{$\begin{array}{l}p- \\
\text { value }\end{array}$} \\
\hline & $\mathrm{n}$ & $\%$ & $\mathrm{n}$ & $\%$ & \\
\hline $21-35$ years & 98 & 78.4 & 3389 & 86.8 & \\
\hline$>35$ years & 25 & 20.0 & 486 & 12.4 & \\
\hline Mother smoking during pregnancy & & & & & 0.54 \\
\hline Yes & 6 & 4.8 & 237 & 6.1 & \\
\hline No & 119 & 95.2 & 3624 & 93.9 & \\
\hline Early psychosocial vulnerability factors in the family & & & & & 0.50 \\
\hline None & 49 & 40.2 & 1685 & 45.1 & \\
\hline Low & 49 & 40.2 & 1462 & 39.1 & \\
\hline Medium & 24 & 19.7 & 578 & 15.5 & \\
\hline High & - & 0.0 & 11 & 0.3 & \\
\hline
\end{tabular}

these respects only minor differences were found. Proportion of mothers, who were born abroad, was slightly higher in the study sample,and mothers in the study sample tend to be slightly older at delivery.

In the univariate analysis in Table 2, it is shown that the duration of total breastfeeding was longer for older mothers $(p=0.01)$. Further, the children's cortisol levels at eight years were higher for those with younger mothers $(p=0.02)$, also for those delivered by cesarean section or with other problems at delivery $(p=0.01)$, and if mothers were smoking during pregnancy $(\mathrm{p}=0.01)$, see Table 2 .

In the multivariate analysis, also described in Table 3, the association between long duration of breastfeeding and lower cortisol levels persisted $(p=0.01)$ even when adjusted for other potential intervening factors like the index of early psychosocial vulnerability in the family and age of mother at delivery. The children had also higher cortisol levels at eight years if the child was not delivered vaginally $(\mathrm{p}=0.01)$ or if the mother smoked during pregnancy $(p=0.03)$.

\section{Discussion}

In our study we show how longer duration of breastfeeding is associated with lower cortisol in hair, a biomarker of stress, of the children at the age of 8 years, which may reflect one important mechanism behind the protective effect of breastfeeding from several diseases. We have previously shown that serious life events early in life are related to the development of diabetes-related autoantibodies [25, 26] and that serious life events during childhood increases the risk of developing Type 1 diabetes three-fold [3]. Our result therefore gives valuable information in our search for mechanisms behind the development of Type 1 diabetes. Early stress is also related to development of several other common health problems e.g. obesity [22, 27]. Breastfeeding has been found to protect against Type 1 diabetes [28] and obesity [21],

Table 2 Perinatal and Sociodemographic Factors and Length of Breastfeeding at Age $8(n=126)$

\begin{tabular}{lll}
\hline & Total length of breastfeeding & p-value \\
\cline { 2 - 3 } & F-value & 0.39 \\
\hline Gender boys/girls & 0.75 & 0.44 \\
Birth weight (low, normal/high) & 0.84 & 0.17 \\
Gestational age (early, normal, over time) & 1.82 & 0.60 \\
Type of delivery (vaginal, section, other problems) & 0.28 & 0.12 \\
Mother parity (firstborn, earlier parity) & 2.51 & 0.01 \\
Age of mother at delivery (from 18 to 40 years & 2.00 & 0.07 \\
Early psychosocial vulnerability. Index of 12 variables *) & 2.40 & 0.43 \\
Mother smoking during pregnancy (not smoke - smoked) & 0.62 &
\end{tabular}

*) Early psychosocial vulnerability: an index including these 12 variables: Father's highest level of education elementary school; Mother's highest level of education elementary school; Father unemployed or on sick leave the year before pregnancy; Mother unemployed or on sick leave during pregnancy; Living in an Apartment, as opposed to own house; Single mother; Parents born abroad; Maternal serious life event during pregnancy; Maternal lack of support during pregnancy; Mother not feeling safe during pregnancy; Mother worried over the possibility of child falling ill with serious disease; Low vs high household income 
Table 3 Multivariate analysis of breastfeeding and some Perinatal and Sociodemographic Factors and Hair Cortisol Concentration at Age 8

\begin{tabular}{|c|c|c|c|c|}
\hline & \multicolumn{4}{|c|}{$\begin{array}{l}\text { Cortisol concentration } \\
\text { at } 8 \text { years }\end{array}$} \\
\hline & \multicolumn{2}{|c|}{ Univariate } & \multicolumn{2}{|c|}{ Multivariate*) } \\
\hline & F-value & p-value & Beta & p-value \\
\hline Gender (boys/girls) & 0.32 & 0.57 & & \\
\hline Birth weight (low, normal, high) & 1.86 & 0.16 & & \\
\hline Gestational age (early, normal, over time) & 0.81 & 0.45 & & \\
\hline Type of delivery (vaginal/section/other problems) & 9.31 & 0.01 & 0.25 & 0.01 \\
\hline Mother parity (firstborn, earlier parity) & 1.74 & 0.19 & & \\
\hline Age of mother at delivery (from 18 to 40 years of age) & 1.95 & 0.02 & -1.08 & 0.28 \\
\hline Early psychosocial vulnerability in the family (index of 12 variables) & 0.25 & 0.86 & -0.47 & 0.64 \\
\hline Mother smoking during pregnancy (non-smoker, smoker) & 8.62 & 0.01 & 0.19 & 0.03 \\
\hline Duration of breastfeeding ( $<1$ month - 10 months) & $-0.23 \#)$ & 0.01 & -2.82 & 0.01 \\
\hline
\end{tabular}

All univariate associations measured by Anova except \#) measured by Pearson correlation

*) Multivariate linear model: $\mathrm{df}=5$, adj $\mathrm{R}^{2}=0.15, F=5.38, p<0.01$

with different possible explanations. One mechanism may be our finding that long breastfeeding is related to lower cortisol in children still at the age of 8 , as cortisol both influences the immune system and increases insulin resistance.

\section{Strengths and weakness of this study}

A weakness of this study is that we had only enough hair in 126 children at the age of 8 years to analyze cortisol in hair in a reliable way. The association between cortisol in hair and chronic stress exists but is of course not simple, but cortisol is known to increase insulin resistance and therefore of interest per se for the development of Type 1 diabetes. Unfortunately, among this followed group few children developed diabetes, so no further analysis was therefore possible. One could question parents own information on duration of breastfeeding, but we have data both from the diary day for day during the first year of life, and from the questionnaires answered at 1 years and 2.5 years of age, and finally we have validated these data from data in well-baby-clinics and found good agreement. This is a strength of this study as well as the design with prospective unbiased collection of data on of psychosocial factors, like serious life events without any knowledge about future development of disease or analyses of cortisol in hair.

Stress in this study is estimated using a biomarker determined with a reliable, robust and accurate method. The fact that the hair is stored for many years does not influence the method or results, and the registered data have of course not been influenced by having been kept for long time in a registry.

\section{Conclusion}

Our results show that longer breastfeeding is associated with lower cortisol levels in the child many years later. These associations should be more elaborated in further studies, and these findings also give some implications for public health. Mothers should be encouraged to breast-feed their children also in the modern society, since breastfeeding promotes health in the child. This information could be given via at the obstetric departments and later at the well-baby clinics.

Acknowlegements We are grateful to all children and parents in ABIS, and thanks the funders who gave us financial support.

\section{Authors' contributions}

$J \mathrm{~L}$ designed and created ABIS, deliverer all data, worked with the manuscript. ÅOF and TF made statistical calculations and worked with the manuscript.

All authors approved the final version.

\section{Funding}

The study has been supported by Barndiabetesfonden (The Swedish Child Diabetes Foundation), FORSS (Research Council of southeast Sweden), and ALF/County Council of Östergötland. The funders had no influence on the design of the study or this report. Open Access funding provided by Linköping University.

Availability of data and materials

The dataset is available from the corresponding author upon reasonable request.

\section{Declarations}

Ethics approval and consent to participate

The ABIS study was approved by the research ethics committees at Linköping University (Dnr 96-287, Dnr 99-321, and Dnr 03-092) and Lund University (LU 83-97), both in Sweden. All participants/caregivers provided informed consent. 


\section{Consent for publication}

Not applicable.

\section{Competing interests}

The authors declare no competing interests.

\section{Author details}

'Crown Princess Victoria Children's Hospital and Division of Pediatrics, Department of Biomedical and Clinical Sciences, Linköping University, SE-581 85 Linköping, Sweden. ${ }^{2}$ Division of Community Medicine, Department of Health, Medicine and Care, Linköping University, SE-581 83 Linköping, Sweden.

Received: 4 November 2020 Accepted: 13 September 2021

Published online: 07 October 2021

\section{References}

1. Selye $H$. The nature of stress. Basal Facts. 1985;7(1):3-11. https://doi.org/1 0.3109/01612848509009447.

2. Chrousos GP, Gold PW. The concepts of stress and stress system disorders. Overview of physical and behavioral homesostasis. JAMA. 1992;267(9):124452. https://doi.org/10.1001/jama.1992.03480090092034.

3. Nygren M, Carstensen J, Koch F, Ludvigsson J, Frostell A. Experience of a serious life event increases the risk for childhood type 1 diabetes: the ABIS population-based prospective cohort study. Diabetologia. 2015;58(6):118897. https://doi.org/10.1007/s00125-015-3555-2.

4. Karlén J, Ludvigsson J, Hedmark M, Faresjö Å, Theodorsson E, Faresjö T. Early psychosocial exposures, hair cortisol levels and disease risk. Pediatrics. 2015; 135(6):e1450-7. https://doi.org/10.1542/peds.2014-2561.

5. Davenport MD, Tiefenbacher S, Lutz CK, Novak MA, Meyer JS. Analysis of endogenous cortisol concentrations in the hair of rhesus macaques. Gen Comp Endocrinol. 2006;147(3):255-61. https://doi.org/10.1016/j.ygcen.2006. 01.005.

6. Roth LS, Faresjö $\AA$, Theodorsson E, Jensen P. Hair cortisol varies with season and lifestyle and relates to human interactions in German shepherd dogs. Sci Rep. 2016:6(1):19631. https://doi.org/10.1038/srep19631.

7. Stalder T, Kirschbaum C. Analysis of cortisol in hair - state of the art and future directions. Brain Behav Immun. 2012;7(7):1019-29. https://doi.org/10.1 016/j.bbi.2012.02.002

8. Karlén J, Frostell A, Theodorsson E, Faresjö T, Ludvigsson J. Maternal influence of child HPA-axis: a prospective study of cortisol levels in hair. Pediatrics. 2013;132(5):e1333-40. https://doi.org/10.1542/peds.2013-1178.

9. Vester VL, van Rossum EF. Clinical applications of cortisol measurements in hair. Eur J Endocrinol. 2015;173(4):M1-M10. https://doi.org/10.1530/EJE-150313.

10. Groeneveld M, Savas M, Van Rossum E, Vermeer H. Children's hair cortisol as a biomarker of stress at school: a follow-up study. Stress. 2020;23(5):590-6.

11. Marteindottir I, Sydsjö G, Faresjö Å, Theodorsson E, Josefsson A. Parityrelated variation in cortisol concentrations in hair during pregnancy. BJOG. 2020;128(4):637-44. https://doi.org/10.1111/1471-0528.16542.

12. Marmot M. Social determinants of health inequalities. Lancet. 2005; 365(9464):1099-104. https://doi.org/10.1016/S0140-6736(05)71146-6.

13. Braveman $P$, Barclay C. Health disparities beginning in childhood: a lifecourse perspective. Pediatrics. 2009;124(Suppl 3):S163-75. https://doi.org/1 0.1542/peds.2009-1100D

14. The Lancet (Editorial). Breastfeeding achieving the new normal. Lancet. 2016;387:404.

15. Victora CG, Bahl R, Barros AJ, et al. (for the lancet breastfeeding series group). Breastfeeding in the $21^{\text {st }}$ century: epidemiology, mechanisms, and lifelong effect. Lancet. 2016;387(10017):475-90. https://doi.org/10.1016/S014 0-6736(15)01024-7.

16. Hanson LA, Söderström T. Human milk: defense against infection. Prog Clin Biol Res. 1981;61:147-59.

17. Moore RE, Townsend SD. Temporal development of the infant gut microbiome. Open Biol. 2019;9(9):190128.

18. Turfkruyer $M$, Verhasselt $V$. Breast milk and its impact on maturation of the neonatal immune system. Curr Opin Infect Dis. 2015;28(3):199-206.

19. Pecoraro L, Agostoni C, Pepaj O, Pietrobelli A. Behind human milk and breastfeeding: not only food. Int J Food Sci Nutr. 2018;69(6):641-6. https:// doi.org/10.1080/09637486.2017.1416459.
20. Ludvigsson J, Ludvigsson M, Sepa A. Screening for prediabetes in the general child population: maternal attitude to participation. Pediatr Diabetes. 2001;2(4):170-4. https://doi.org/10.1034/j.1399-5448.2001.20405.x.

21. Brekke H, Ludvigsson J, Odijk J, Ludvigsson J. Breastfeeding and introduction of solid foods in Swedish infants: the all babies in Southeast Sweden study. Br J Nutr. 2005;94(3):377-82. https://doi.org/10.1079/BJN2 0051499 .

22. Huus K, Ludvigsson JF, Enskär K, Ludvigsson J. Exclusive breastfeeding of Swedish children and its possible influence on the development of obesity: a prospective cohort study. BMC Pediatr. 2008;8(1):42. https://doi.org/10.11 86/1471-2431-8-42.

23. Cooper GA, Kronstrand R, Kintz P. Society of Hair Testing guidelines for drug testing in hair. Forensic Sci Int. 2012;218(1-3):20-4. https://doi.org/10.1016/j. forsciint.2011.10.024

24. Morelius E, Nelson N, Theodorsson E. Salivary cortisol and administration of concentrated oral glucose in newborn infants: improved detection limit and smaller sample volumes without glucose interference. Scand J Clin Lab Invest. 2006;64(2):113-8. https://doi.org/10.1080/00365510410004452.

25. Sepa A, Wahlberg J, Vaarala O, Frodi A, Ludvigsson J. Psychological stress may induce diabetes-related autoimmunity in infancy. Diabetes Care. 2005; 28(2):290-5. https://doi.org/10.2337/diacare.28.2.290.

26. Sepa A, Frodi A, Ludvigsson J. Mothers' experiences of serious life events increase the risk of diabetes-related autoimmunity in their children. Diabetes Care. 2005;28(10):2394-9. https://doi.org/10.2337/diacare.28.10.2394.

27. Koch FS, Sepa A, Ludvigsson J. Psychological stress and obesity. J Pediatr. 2008;153(6):839-44. https://doi.org/10.1016/j.jpeds.2008.06.016.

28. Rewers M, Ludvigsson J. Environmental risk factors for type 1 diabetes. Lancet. 2016:387(10035):2340-8.

\section{Publisher's Note}

Springer Nature remains neutral with regard to jurisdictional claims in published maps and institutional affiliations.

Ready to submit your research? Choose BMC and benefit from

- fast, convenient online submission

- thorough peer review by experienced researchers in your field

- rapid publication on acceptance

- support for research data, including large and complex data types

- gold Open Access which fosters wider collaboration and increased citations

- maximum visibility for your research: over $100 \mathrm{M}$ website views per year

At BMC, research is always in progress.

Learn more biomedcentral.com/submissions 